\title{
Study of Structural and Optical Properties of ZnS:Ni Thin Films Prepared by Dip Coating Method
}

\author{
C Gunasekaran, ${ }^{\star}$ V Senthilkumar, ${ }^{\dagger}$ P Kokila, ${ }^{\ddagger}$ S Uma ${ }^{\S}$ and \\ S Banumathi**
}

\section{Abstract}

Adherent and uniform films of $\mathrm{ZnS}$ and $\mathrm{ZnS}: \mathrm{Ni}$ were deposited reproducibly by Dip coating method onto a glass substrate, under acidic conditions from solutions containing Zinc Nitrate, Nickel Nitrate, Ammonium Nitrate, Sodium citrate, thiourea and distilled water. The growth of $\mathrm{ZnS}$ thin films on glass substrates have been thoroughly investigated by SEM, EDAX and $X$ - ray diffraction techniques. The grain sizes (D) of crystallites were estimated using the Scherrer's formula. Depending on selection of precursors and presence of dopant, $\mathrm{ZnS}$ and ZnS films can be of Sphalenite or wurtzite structure. The effect of the dopant on the crystallinity and surface morphology of ZnS thin films have been studied. The surface morphology, which has been evaluated by scanning electron microscope (SEM), shows a relatively flat and uniform surface.

\footnotetext{
* Corresponding author Department of Physics, Karpagam University, Coimbatore-641 021; guna8965@gmail.com
}

† Department of Physics, Karpagam University, Coimbatore-641 021; vsenkumar@yahoo.com

‡ Department of Physics, Karpagam University, Coimbatore-641 021

$\S$ Postgraduate and Research Department of Physics, Govt Arts College (Autonomous), Karur-639005

** Postgraduate and Research Department of Physics, Govt Arts College (Autonomous), Karur-639005 
Keywords: ZnS thin films, semiconductor photo catalysis, photo electrodes, and reductive activity.

\section{Introduction}

Zinc Sulphide $(\mathrm{ZnS})$ is an important semiconducting material with a wide direct band gap of $3.65 \mathrm{eV}$ in the bulk form [1] which crystallizes in both cubic and hexagonal forms. A diverse range of applications exists for thin films of ZnS, primarily within photovoltaic, optoelectronic devices. Semiconductor photocatalysis has directed increasing interest to water splitting in the photo electrochemical process as it applies to solar energy conversion. The conversion efficiency of water photo electrolysis in the context of solar energy conversion is determined principally by the properties of the visible-light-induced photo electrodes in the photelectrochemical cells (PECs). However, the materials of the visible-light-driven photo electrodes used in PECs should meet two fundamental requirements: They must have a narrow band gap to attain maximal absorption of solar energy and the band edge of conduction band has to be more negative than the reduction potential of $\mathrm{H}_{2} \mathrm{O}$ to produce $\mathrm{H}_{2}$ [1]. It is well-known that the position of the conduction band of a semiconductor is a key factor in ensuring an effective photocatalytic $\mathrm{H}_{2}$ evolution. The deeper the conduction band, the stronger its reductive activity, and the higher its photocatalytic $\mathrm{H}_{2}$ production. The level of the conduction band of $\mathrm{ZnS}$ is so negative that it can be a high efficient photocatalyst for water splitting. However, use of ZnS is still limited to UV light due to this large band gap, $3.6 \mathrm{eV}$ [2]. Therefore, many studies have been carried out to develop a visible-light active $\mathrm{ZnS}$ through the doping of metal ions. Doping of $\mathrm{ZnS}$ by the transition metal ions $\mathrm{Mn}^{2+}[3,4], \mathrm{Cu}^{2+}[5,6]$ and $\mathrm{Ni}^{2+}[7]$, has received considerable attention in applications in electroluminescence devices, phosphors, light emitting displays and optical sensors. The aim of this paper is to study the structural and optical properties of $\mathrm{ZnS}$ thin films obtained on glass substrates. 


\section{Experimental}

ZnS:Ni thin films are obtained by dip-coating method in air atmosphere. Cationic solutions of zinc nitrate $(0.4 \mathrm{M})$ nickel nitrate $(0.4 \mathrm{M})$, ammonium nitrate $(0.4 \mathrm{M}$, buffer solution), sodium citrate $(0.5 \mathrm{M}$, complexing agent) and thiourea $(0.4 \mathrm{M})$ were added sequentially under constant stirring. Glass substrates were placed vertically into the deposition solution at $80{ }^{\circ} \mathrm{C}$ for 30 minutes and for two hour in another solution of same composition. The thin films annealed for one hour at $200{ }^{\circ} \mathrm{C}$ in hot air oven. The process of thin film formation is shown in Fig. 1.

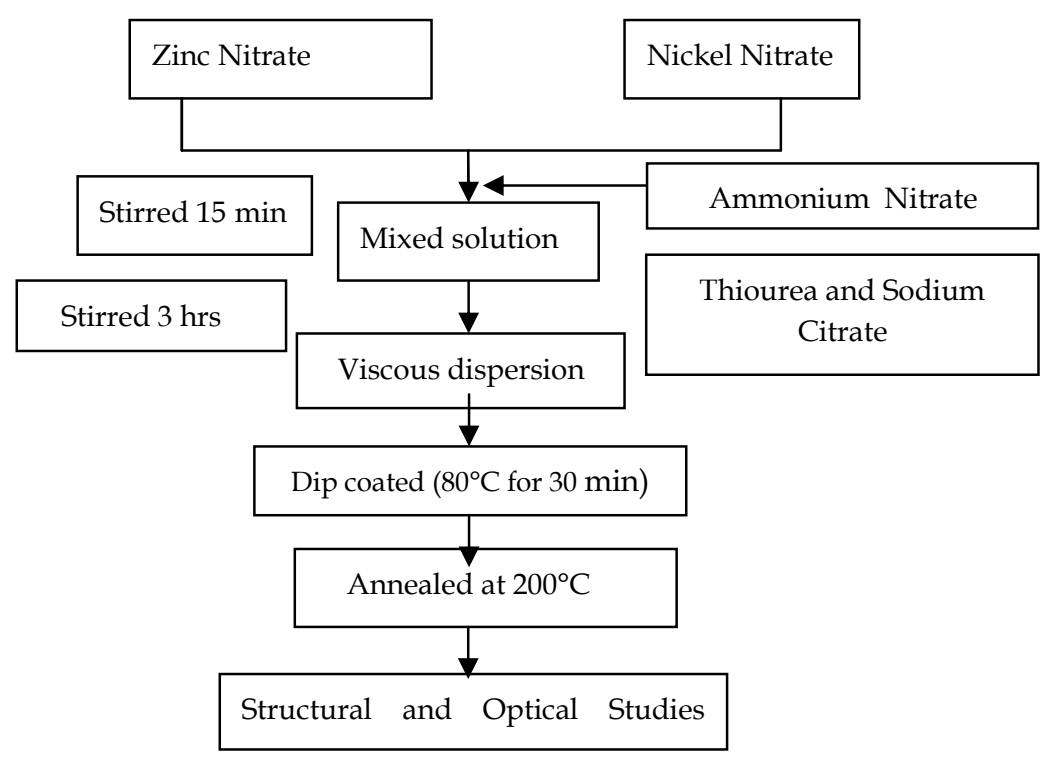

Fig. 1. Preparation steps of pure and Ni-doped $\mathrm{ZnS}$ thin films by sol-gel dip coating method.

\section{Results and discussion}

The formation of ZnS thin films using Dip coating method can be explained that $\mathrm{Zn}^{2+}$, resulting from the dissociation of $\mathrm{Zn}\left(\mathrm{NH}_{3}\right)_{4}{ }^{2+}$ complex ions, would combine with $\mathrm{S}^{2-}$ ions, resulting from the hydrolysis of the thiourea in a basic aqueous solution, to form ZnS on the substrate, followed by a heterogeneous reaction and precipitation [8]. After the deposition, a yellowish 
film of Ni-doped ZnS formed and a bright silvery ZnS film was observed on the glass substrates.

The following chemical reaction leads to the formation of $\mathrm{ZnS}$ :

$$
\begin{aligned}
& \mathrm{Zn}\left(\mathrm{NO}_{3}\right)_{2} \rightarrow \mathrm{Zn}^{2+}+\mathrm{NO}_{3}{ }^{2-} \\
& \mathrm{CS}\left(\mathrm{NH}_{2}\right)_{2}+\mathrm{OH}^{-} \rightarrow \mathrm{SH}^{-}+\mathrm{CH}_{2} \mathrm{~N}_{2}+\mathrm{H}_{2} \mathrm{O} \\
& \mathrm{SH}++\mathrm{OH}^{-} \rightarrow \mathrm{S}^{2-}+\mathrm{H}_{2} \mathrm{O} \\
& \mathrm{Zn}^{2+}+\mathrm{S}^{2-} \rightarrow \mathrm{ZnS}
\end{aligned}
$$

The X-ray diffractograms of undoped and doped ZnS thin films deposited on glass substrates are represented in Fig. 2a \& 2b. For the undoped sample, the three major diffraction peaks are corresponding to (008), (104) and (110) planes of hexagonal crystalline ZnS, respectively. The ZnS sample exhibits a very strong diffraction peak at $2 \theta=29.3^{\circ}$ indicating $\mathrm{ZnS}$ sample had a preferential orientation along the (008) plane(JCPDS no. 36-1450). For the Ni-doped samples, the hexagonal phase of $\mathrm{ZnS}$ was significantly reduced with doping of nickel ions in the solution and no characteristic peaks of nickel containing compounds are detected. Moreover, the diffraction peak of (008) was shifted to higher angles for the $\mathrm{Ni}$ doped samples. Since the ionic radius of $\mathrm{Ni}^{2+}(0.69 \AA)$ is smaller than that of $\mathrm{Zn}^{2+}(0.74 \AA)$, it can be inferred that nickel ions might insert into the structure of $\mathrm{ZnS}$ and located at interstices or occupied some of the lattice sites of $\mathrm{ZnS}$.

From the XRD profiles, the inter-planar spacing $\mathrm{d}_{h k l}$ was calculated for the (101) plane using the Bragg's relation

$$
d_{h k l}=\frac{n \lambda}{2 \sin \theta}
$$

where, $\lambda$ is the wavelength of the $X$-ray used, $d$ is the lattice spacing, $\mathrm{n}$ is the order number and $\theta$ is the Bragg's angle. The factor $d$ is related to $(h k l)$ indices of the planes and the dimension of the unit cells. The crystallite size (D) of the films was calculated from the Debye Scherrer's formula from the full-width at halfmaximum (FWHM) $\beta$ of the peaks expressed in radians. 


$$
D=\frac{0.94 \lambda}{\beta \cos \theta}
$$

where, $\beta$ is the FWHM calculated from the (101) plane.
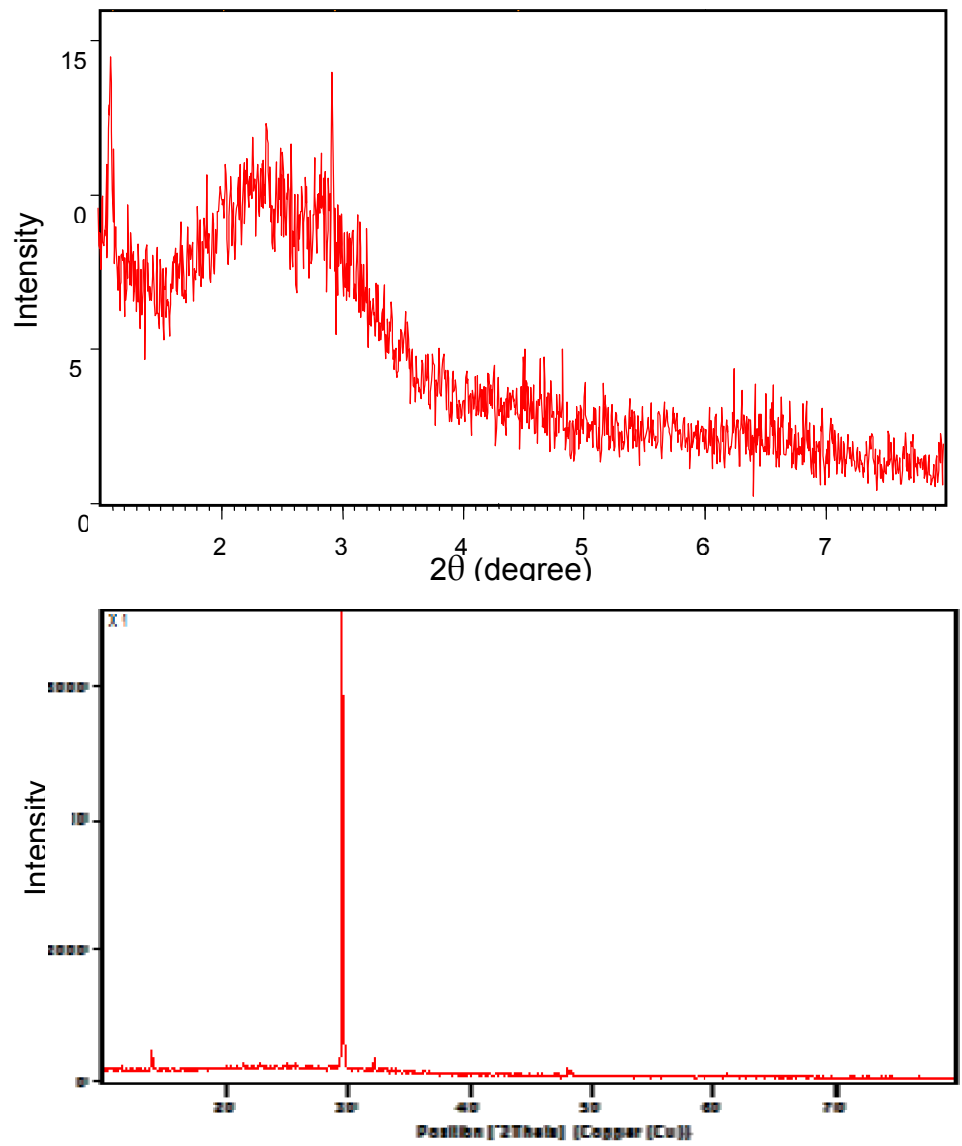

Fig. 2a \& 2b. XRD Patterns of pure and Ni doped ZnS

The strain is calculated by using the relation

$$
\beta=\frac{\lambda}{D \cos \theta}-\varepsilon \tan \theta
$$


where $\varepsilon$ is an internal micro strain, a dimensionless ratio, is defined as the ratio of elongation with respect to the original length.

The dislocation density $(\delta)$, defined as the length of dislocation lines per unit volume of the crystal and has been calculated by using the formula

$$
\delta=\frac{1}{D^{2}}
$$

The doping of nickel results in increase of dislocation density, the formation of the some defects in the crystal structures, which effectively decreases the intensity of the hexagonal ZnS phase. Therefore, at high doping level, film growth turns to non-oriented and with poor crystallinity. Such a change of the crystallographic structure of Ni-doped ZnS may result in a change of electronic structure, which enables the absorption edge to shift towards longer wavelengths after the addition of $\mathrm{Ni}$.

The lattice parameter ' $a$ ' can be calculated from the equation given below for cubic geometry.

$$
\frac{1}{d^{2}}=\frac{\left(h^{2}+k^{2}+l^{2}\right)}{a^{2}}
$$

where, hkl represent the lattice planes. The values of particle size, strain and dislocation density for the films annealed at different temperatures are shown in Table 1. 


\begin{tabular}{|l|l|l|l|l|l|}
\hline Element & $\begin{array}{l}\text { Particle } \\
\text { nm(size D }\end{array}$ & $\begin{array}{l}\text { Dislocation } \\
\text { density } \\
\delta\left(\times 10^{15}\right. \\
\left.\operatorname{lin} / \mathrm{m}^{2}\right)\end{array}$ & $\begin{array}{l}\text { Strain } \varepsilon \\
\times 10\left({ }^{3-} \text { lin }\right. \\
\left.\mathrm{m}^{4-}\right)\end{array}$ & $\begin{array}{l}\text { Lattice } \\
\text { constant a } \\
\times 10\left({ }^{10-}\right) \mathrm{m}\end{array}$ & $\begin{array}{l}\text { Lattice } \\
\text { spacing d } \\
\times 10\left({ }^{10-}\right) \mathrm{m}\end{array}$ \\
\hline ZnS & 40.85 & 6 & 2.57 & 6.21 & 3.193 \\
\hline ZnS:Ni & 35.65 & 7.87 & 2.98 & 6.29 & 3.256 \\
\hline
\end{tabular}

Table 1: Structural parameters of pure and Ni- doped $\mathrm{ZnS}$ thin films

From the Fig. $3 a \& 3 b$, we see that the $\mathrm{ZnS}$ film contains a hierarchical structure, and the average grain size is in the approximate range of $500 \mathrm{~nm}$, in which micro particles from the solution adhere onto the substrate through a cluster-by-cluster deposition process to produce rod like branches. The surface morphology of the Ni-doped ZnS film is drastically different if the film is constituted by small and densely packed aggregates. So some crystals type structures are seen in the Ni-doped SEM micrographs in Fig. $3 \mathrm{~b}$. When $\mathrm{Ni}$ ions are added to the solution, nucleation and crystal growth obviously change. More and more microspheres appear through ion-by-ion condensation, which increases the compactness of the film. It is a well-known fact that the growth of a film in a dip coating can be achieved by using ammonia as the complexing agent to control the release of metal ions. In this case, $\mathrm{Ni}$ ions could reduce the migration of complex ions, thus leading to a lower reaction rate in freeing $S$ from the hydrolysis of the thiourea and forming a uniform and dense film.
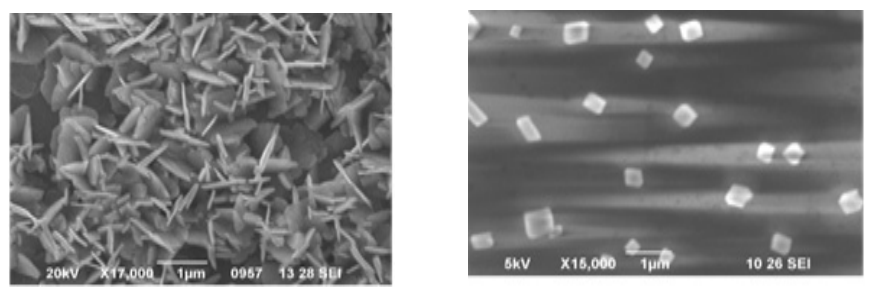

Fig. 3a \& 3b SEM image of pure and Ni doped $\mathrm{ZnS}$ 

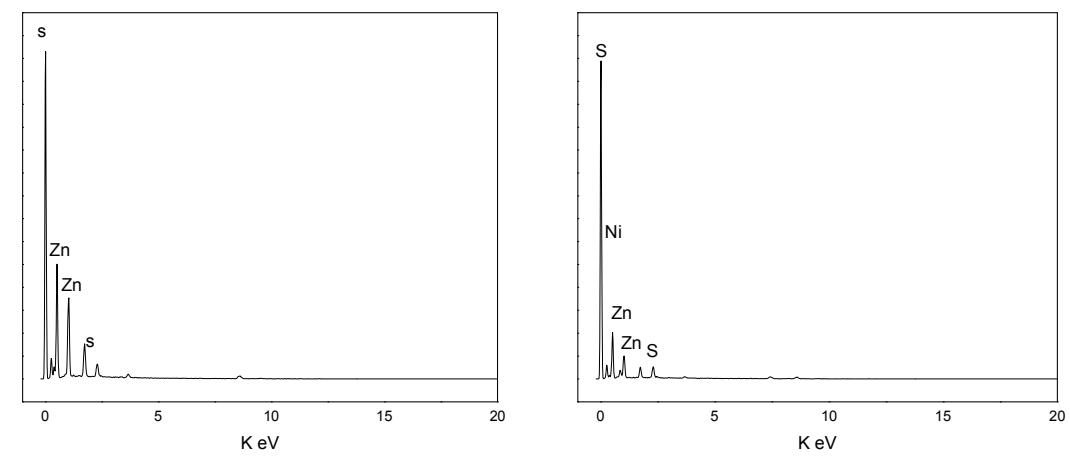

Fig. 4a \& 4b. EDAX patterns of pure and Ni doped $\mathrm{ZnS}$

\begin{tabular}{|c|c|c|}
\hline Element & Atomic (\%) & Weight (\%) \\
\hline \multicolumn{3}{|c|}{ Pure - ZnS } \\
\hline Zn & 59.65 & 42.03 \\
\hline $\mathrm{S}$ & 40.35 & 57.97 \\
\hline \multicolumn{3}{|c|}{ ZnS : Ni } \\
\hline Zn & 25.14 & 27.53 \\
\hline $\mathrm{S}$ & 57.09 & 40.52 \\
\hline $\mathrm{Ni}$ & 17.77 & 23.09 \\
\hline
\end{tabular}

Table 2: Compositional analysis of pure and Ni- doped $\mathrm{ZnS}$ thin films.

The composition of the pure ZnS films were found to be more or less the same as doped $\mathrm{ZnS}$ there was no significant variation in the composition. It is observed in the Table 2 and in the Fig. $4 a$ \& 4 b. The absorption and transmittance spectra of undoped and $\mathrm{Ni}$ doped ZnS thin films are shown in Fig. 5a \& 5b respectively. The crystallographic structure of $\mathrm{Ni}$ doped ZnS may result in a 


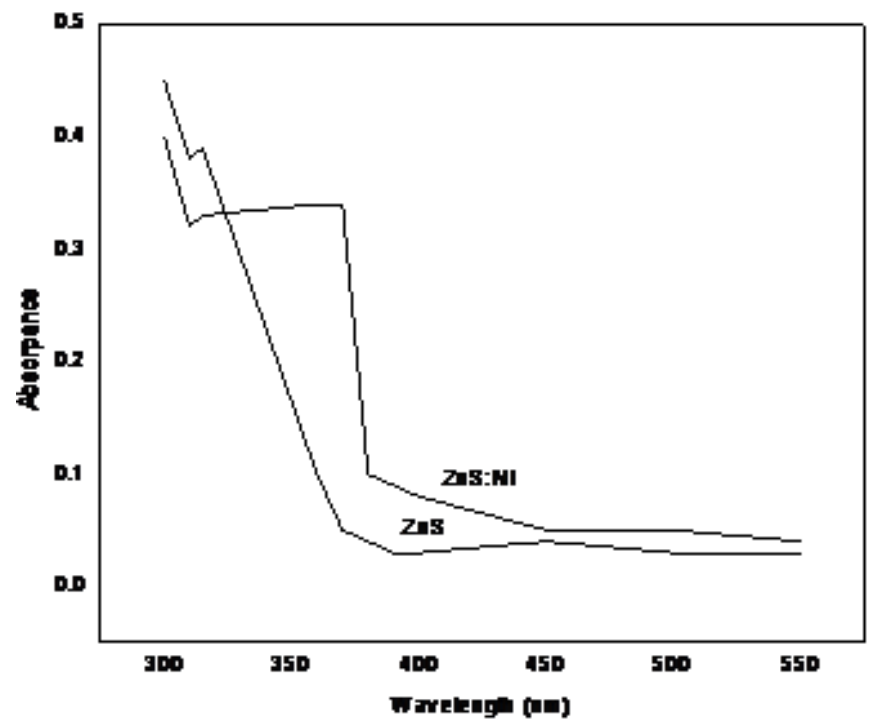

Fig. 5a. Absorbance spectra of pure and Ni doped $\mathrm{ZnS}$

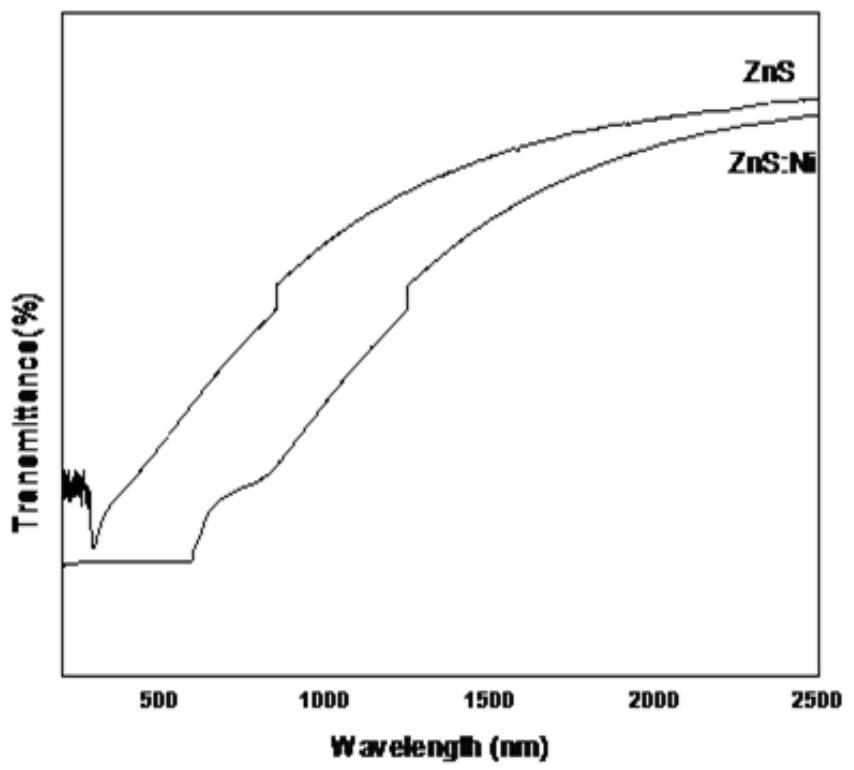

Fig. 5b. Transmittance spectra of pure and Ni doped ZnS

change of electronic structure, which enables the absorption edge to shift towards longer wavelengths after the addition of $\mathrm{Ni}$. The absorption edge shifting towards visible region explained the yellowish colour for the Ni-doped $\mathrm{ZnS}$ thin films. The red shift 
in the absorption spectra may be due to larger grain size [10]. This can be seen from the SEM micrographs in Fig. 3a \& 3b. The maximum transmittance of $\mathrm{ZnS}$ in the range around $950 \mathrm{~nm}$ is about $70 \%$. Based on the transmittance spectra of the samples, the optical constants and the film thickness can be calculated by means of the following formula [11].

Using the transmittance spectrum the optical constants such as extinction coefficient are calculated and plotted as a function of photon energy is shown in Fig. 6. To quantify the optical bandgap $\left(\mathrm{E}_{\mathrm{g}}\right)$ of films, the following formula is employed in the high absorbance region of the transmittance spectra,

$$
(\alpha h v)^{2}=A\left(h v-E_{g}\right)^{n}
$$

Where, $\mathrm{a}$ is the absorption coefficient, $\mathrm{A}$ is a constant which is independent of photon energy and $\mathrm{h} v$ is the photon energy, $\mathrm{E}_{\mathrm{g}}$ is the optical band gap and $n$ has four numeric values $(1 / 2$ for allowed direct, 2 for allowed indirect, 3 for forbidden direct and $3 / 2$ for forbidden indirect optical transitions). In this work, direct band gap was determined by plotting $(a h v)^{2}$ versus hv curves respectively, with the extrapolation of linear region to low energies.

Energy band gaps of $3.37 \mathrm{eV}$ for a $\mathrm{ZnS}$ film and $3.02 \mathrm{eV}$ for a $\mathrm{Ni}$-doped ZnS film are determined at the absorption edge as the intersection point of extrapolation from the straight region of the plot. The band gap of the undoped $\mathrm{ZnS}$ film is somewhat smaller than the typical value of the bulk ZnS ( 3.6 $\mathrm{eV}$ ), which is probably due to the annealing effect. Such annealing effect has been reported for chemical bath 


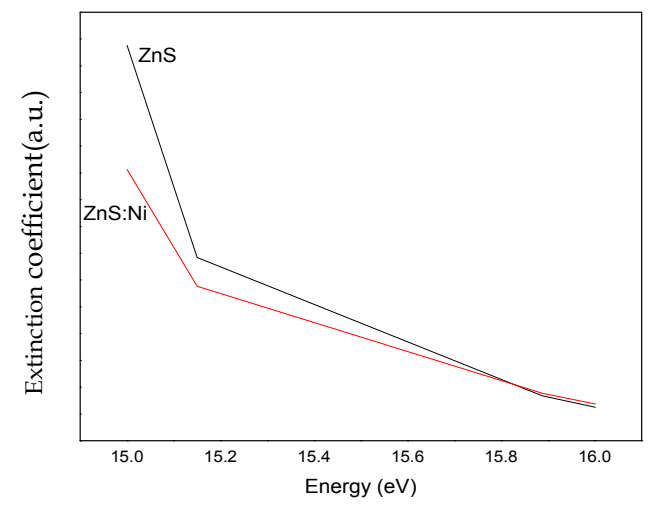

Fig. 6. Extinction coefficient (a.u.) vs. photon energy (eV)

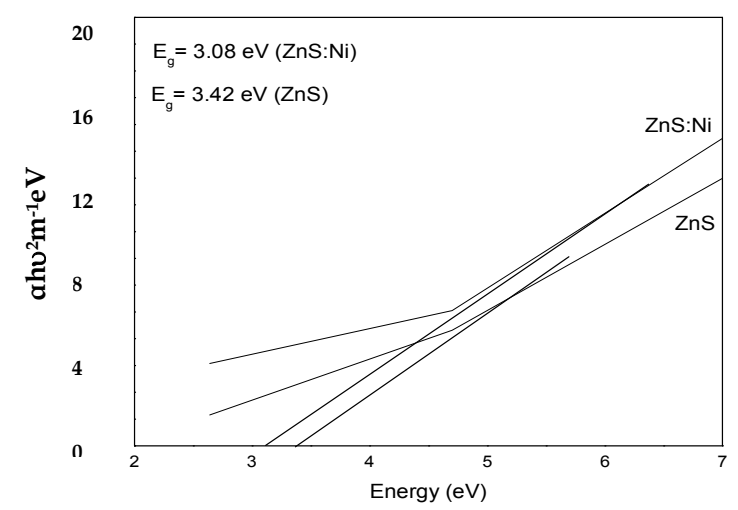

Fig. 7. The plot of variation of $(\alpha h v)^{2}$ vs. hv of the pure and Ni doped $\mathrm{ZnS}$ films.

deposited ZnS films [12-14]. The decrease in the band gap of Nidoped ZnS thin film is related to the deformation of the structure. The nickel from dip coating process can replace either substitutional or interstitial the zinc in the $\mathrm{ZnS}$ lattice creating the structure deformation, Similar results, relate to poor crystallinity, the formation of copper-based complexes, and the decrease of the band gap of $\mathrm{ZnS}$, were observed by Oztas [15] in their study of Cu-doped ZnS thin films. 


\section{Conclusion}

Thin films of undoped and Ni-doped ZnS are successfully prepared on glass substrates using dip coating technique. The films are characterized by means of scanning electron microscopy and X-ray diffraction. SEM images confirm the formation of uniform grains for all samples. XRD studies show that $\mathrm{ZnS}$ films grown on glass preferentially orientation along the (008) direction. It has been established that the addition of nickel affects the growth mechanisms of films, the crystallographic structure, the absorption spectra. In the case of undoped $\mathrm{ZnS}$ thin film,rod-like branches with the wurtzite structure have been observed by SEM and XRD. The XRD characteristics of $\mathrm{Ni}$-doped $\mathrm{ZnS}$ thin films indicate that there is no Ni-S phase formation. The difference in the absorption spectra and the band gaps between undoped and doped $\mathrm{ZnS}: \mathrm{Ni}$ may result from crystallinity and grain size effects, as supported by XRD and SEM analysis.

\section{References}

[1] N. Armor," The multiple roles for catalysis in the production of $\mathrm{H} 2$, ," Appl. Catal. A, vol. 176, p. 159, 1999. http://dx.doi.org/ 10.1016/ S0926-860X(98)00244-0.

[2] K. W. Cheng, C. M. Huang, G. T. Pan, P. C. Chen, T. C. Lee and K. Yang, "Physical properties of AgIn5S8 polycrystalline films fabricated by solution growth technique," Mater. Chem. Phys., vol. 108, p. 16, 2008. http://dx.doi.org/10.1016/ j.matchemphys.2007.08.035.

[3] S. Erat, H. Metin and M. Ari, "Influence of the annealing in nitrogen atmosphere on the XRD, EDX, SEM and electrical properties of chemical bath deposited CdSe thin films," Mater. Chem. Phys., vol. 111, p. 114, 2008. http://dx.doi.org/10.1016/ j.matchemphys.2008.03.021.

[4] B. Y. Geng, L. D. Zhang, G. Z. Wang, T. Xie, Y. G. Zhang and G. W. Meng, "Synthesis and photoluminescence properties of ZnMnS nanobelts," Appl. Phys. Lett., vol. 84, p. 2157, 2004. http://dx.doi.org/10.1063/1.1687985.

[5] Khosravi, M. Kundu, L. Jatwa, S. K. Deshpande, U. A. Bhagawat, . Sastry and S. K. Kulkarani, "Green luminescence from copper doped zinc sulphide quantum particles," Appl. Phys. Lett., vol. 67, p. 2702, 1995. http://dx.doi.org/10.1063/1.114298. 
[6] S. Lee, D. Song, D. Kim, J. Lee, S. Kim, I. Y. Park, Y. D. Choi, "Effects of synthesis temperature on particle size/shape and photoluminescence characteristics of $\mathrm{ZnS}: \mathrm{Cu}$ nanocrystals," Mater. Lett., vol. 58, p. 342, 2004. http://dx.doi.org/10.1016/S0167577X(03)00483-X.

[7] P. Yang, M. Lu, D. Xu, D. Yuan, J. Chang, G. Zhou and M. Pan, "Strong green luminescence of Ni2+-doped ZnS nanocrystals," Appl. Phys. A, vol. 74, p. 257, 2002. http://dx.doi.org/ 10.1007/ s003390100889

[8] C. M. Huang, L. Chen, G. T. Pan, T. C. K. Yang, W. S. Chang and K. W. Cheng, "Effect of $\mathrm{Ni}$ on the growth and photoelectrochemical properties of ZnS thin films," Mater. Chem. Phys., vol. 117 p. 156, 2009. http://dx.doi.org/10.1016/j.matchemphys.2009.05.026.

[9] R. C. Hoffmann, L. P. H. Jeurgens, S. Wildhack, J. Bill and F. Aldinger, "Relation between particle growth in solution and composition of mixed titania/vanadium oxide films: Implications for chemical bath deposition," Chem. Mater., vol. 18, p. 4465, 2006. 1094-DD03-08.

[10]Z. H. Lin and C. R. Wang, "Evidence on the size-dependent absorption spectral evolution of selenium nanoparticles," Mater. Chem. Phys., vol. 92, pp. 591, 2005. http://dx.doi.org/10.1016/ j.matchemphys.2005.02.023.

[11]S. Agilan, D. Mangalaraj, S. K. Narayandass and G. M. Rao, "Effect of thickness and substrate temperature on structure and optical band gap of hot wall-deposited \$CuInSe_\{2\}\$ polycrystalline thin films," Physica B vol. 365, p. 93, 2005. http://eprints.iisc.ernet.in/id/ eprint/3612.

[12] O. Oladeji and L. Chow, "A study of the effects of ammonium salts on chemical bath deposited zinc sulfide thin films," Thin Solid Films, vol. 339, p. 148, 1999. http:/ / dx.doi.org/10.1016/S0040-6090(98)01326-1.

[13]H. Lee, W. C. Song, K. J. Yang and Y. S. Yoo, "Characteristics of the $\mathrm{CdZnS}$ thin film doped by indium diffusion," Thin Solid Films, vol. 416, p. 184, 2002. http:/ / dx.doi.org/10.1016/S0040-6090(02)00702-2.

[14]S. D. Sartale, B. R. Sankapal, M. Lux-Steiner and A. Ennaoui, "Preparation of nanocrystalline $\mathrm{ZnS}$ by a new chemical bath deposition route," Thin Solid Films, vol. 480, p. 168, 2005. http:/ / dx.doi.org/10.1016/j.tsf.2004.11.054.

[15]M. Oztas, M. Bedir, A. N. Yazici, E. V. Kafadar and H. Toktamis, "Characterization of copper-doped sprayed ZnS thin films" Physica B, vol. 381, p. 40, 2006. http://dx.doi.org/10.1016/j.physb.2005.12.248. 